\title{
DEXTROCARDIA, SITUS INVERSUS TOTALIS AND APPENDICULAR ABSCESS
}

\author{
By N. Nagaratnam, M.B.B.S.(Ceylon), and L. S. Kotagama, M.B.B.S.(Ceylon) \\ Formerly House Physicians, General Hospital, Colombo
}

We wish to report a case of diagnosed appendicular abscess associated with Dextrocardia and Situs Inversus Totalis. Its comparative rarity makes it of considerable interest. The discovery of dextrocardia is often accidental at a life insurance or mass X-ray examination. The heart and all the thoracic and abdominal viscera are completely transposed but as their mutual relationship is unaltered, ' a mirror image' of the normal results.

Cockayne (1938) gives a figure of one in $19,500$. Tanner-Cain and Crump (195I) have reported an incidence of one in 35,000 of Situs Inversus Totalis in the United States Army recruits in 1947.

\section{Case Report}

A 26-year old housewife entered the General Hospital, Colombo, because of abdominal pain of ten days duration. She had had fever for some days prior to admission. On the morning of admission she had nausea and a temperature of IOI ${ }^{\circ} \mathrm{F}$., but there were no chills, vomiting, diarrhoea, constipation or urinary symptoms.

2 Physical examination revealed a well developed young woman. The apex beat was palpable in the right fifth intercostal space about $3 \frac{1}{2}$ in. from the midline. The cardiac dullness was on the right side, and the heart sounds were similarly disposed. Both sounds were heard at the apex. A Grade 2 soft systolic murmur was heard over the right second intercostal space.

There was dullness on the left side. The abdomen was soft. There was a tender mass about the size of a small orange in the left iliac fossa, which did not extend into the loin. There was no rigidity, but slight guarding was present. Bowel movements were heard.

Urinanalysis showed a few epithelial cells, 6 to 8 pus cells a field, 2 to 3 red cells a field, and a few calcium oxalate crystals. The white cell count was $2 \mathrm{I}, 000$ per $\mathrm{cmm}$. The differential count was, polymorphs 86 per cent. and lymphocytes 14 per cent. Rectal examination showed a mass in the left lateral wall which was tender.

A diagnosis of appendicular abscess with dextrocardia and Situs Inversus Totalis was made.
Teleradiogram of heart showed a 'mirror image' of the heart and thorax, the aortic arch lying on the right side, the left wing of the diaphragm being higher than the right. Barium meal examination at a later date showed the stomach on the right side, thus confirming that the high probability of the left sided dullness being liver.

The electrocardiographic changes were inversion of all waves in lead $\mathrm{I}$; lead 2 and 3 had changed places.

After a period of conservative treatment laparotomy was done. The appendix was found diseased and was in the left iliac fossa. The positions of the stomach and liver were found reversed.

\section{Discussion}

The term Dextrocardia is properly reserved for those cases where the position of the heart is the result of a developmental abnormality and not due to disease or other changes in the adjacent structures.

Several varieties of dextrocardia are recognized. Dextrocardia with Situs Inversus Totalis is the commonest variety of dextrocardia and is of no clinical significance. In isolated dextrocardia without transposition of the viscera, there is heterotaxia of the heart alone with normal position of the viscera. Dextrocardia may be associated with congenital defects of the diaphragm.

Lochte as quoted by Ballantyne (1904) believes that no instance has yet been put on record in which clearly marked Situs transversus of one body cavity was accompanied by entirely normal arrangement of those in other cavities. He states that the exceptions that occur are based on the results of clinical examination only, and are therefore not free from possible errors.

Our knowledge of the origin of Situs inversus is far from complete. There are many theories, all of which are not fully explanatory.

One theory is that the embryonic organs in assuming their respective positions develop in a definite dependent sequence. If for some reason the initial organ of such an interdependent system undergoes a reversal in position all succeeding 
stages are correspondingly affected. Serres as quoted by Ballantyne ( 1904 ) regarded the liver as the viscus whose position and movements determined those of the other organs.

Virchow as quoted by Ballantye (1904) carried the theory a little further and regarded the kind of torsion found in the umbilical cord as the determining cause of the position of the liver. Later it was found not to be so. No cause was found for the displacement of the liver, further inversion was found to occur long before the appearance of the liver buds. Still more it was found that displacement of the liver occurred without inversion of the other organs.

This conception of the liver being the controlling factor became modified in consequence of the more recent studies of the problem of asymmetry in the viscera. The gut was considered the pivot around which the rest of the organs operate, and the normal spiral organization of the developing gut which when reversed in direction automatically led to transposition. Some objections have been advanced against this view.

Taruffi as quoted by Ballantyne (1904) is of the opinion that it is the unequability of the two halves of the area vasculosa in the case of the embryo chick which is concerned with the inversion of the viscera. This theory goes back to the reason why the embryo lies on the vascular area in just the way it does in normal cases and in a different way in inversion. It may prove helpful, if at this point certain facts emphasized by Ballantyne (1904) are briefly summarized.

I. The ontogeny of the mammal differs from that of the bird ovum and embryo and as such it is doubtful as to how far deductions can be drawn from observations and experiments on the hen's egg.

2. The idea that the individual with inversion of the viscera is the right side survivor of uniovular twins though a fascinating one is not supported by facts.
3. He states that for a theory of heterotaxy to be satisfactory it ought to include an explanation of the partial cases of transposition in which the heart alone or one of the abdominal organs alone is displaced.

4. It is useless to look for causes of heterotaxy in late embryonic life, and to do so is only to introduce endless difficulties.

5. There is reason to believe that heterotaxy is determined by causes acting on the organism on the germinal or pre-embryonic period just as it seems clear that the normal asymmetry of the body is also decided at this early period.

\section{Summary}

A case of dextrocardia situs inversus totalis and appendicular abscess which has been clinically diagnosed and later confirmed at operation has been described. The importance of congenital dextrocardia belongs to the identification of transposed viscera, when these call for surgical treatment.

The teratogenesis of situs inversus is still not fully understood. Some of the theories have been discussed. In spite of the absence of any cogent evidence it is difficult to escape the conclusion that the probabilities point to the origin of the inversion of the viscera in the pre-embryonic period.

\section{Acknowledgments}

We wish to thank Dr. D. F. de S. Gunawardena, Visiting Surgeon, General Hospital for permission to publish this case, and to Dr. F. L. W. Jayawardene, University of Ceylon, for his valuable criticism.

\section{BIBLIOGRAPHY}

BALLANTYNE, J. W. (1904), Manual of Antenatal Pathology and Hygiene, William Green \& Sons, Edinburgh, p. 603-4.

COCKAYNE, E. A. (1938), Quart. F. Med., 3I, 479.

TANNER-CAIN, N., and CRUMP, E. P. (1951), f. Pediat., 38, 199 .

\section{RUTHIN CASTLE, NORTH WALES}

A Clinic for the diagnosis and treatment of Internal Diseases (except Mental or Infectious Diseases). The Clinic is provided with a staff of doctors, technicians and nurses.

The surroundings are beautiful. The climate is mild. There is central heating throughout. The annual rainfall is 30.5 inches, that is, less than the average for England.

The Fees are inclusive and vary according to the room occupied.

For particulars apply to THE SECRETARY, Ruthin Castle, North Wales. 